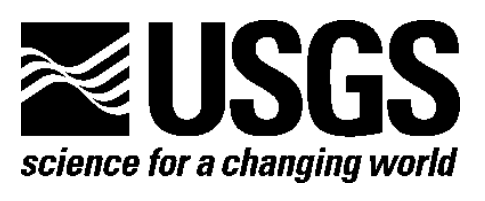

\title{
Database of Recent Tsunami Deposits
}

By Robert Peters and Bruce E. Jaffe

Open-File Report 2010-1172

U.S. Department of the Interior

U.S. Geological Survey 


\title{
U.S. Department of the Interior \\ KEN SALAZAR, Secretary
}

\author{
U.S. Geological Survey \\ Marcia K. McNutt, Director
}

U.S. Geological Survey, Reston, Virginia 2010

For product and ordering information:

World Wide Web: http://www.usgs.gov/pubprod

Telephone: 1-888-ASK-USGS

For more information on the USGS-the Federal source for science about the Earth, its natural and living resources, natural hazards, and the environment:

World Wide Web: http://www.usgs.gov

Telephone: 1-888-ASK-USGS

Suggested citation:

Peters, Robert, and Jaffe, B.E., 2010, Database of recent tsunami deposits: U.S. Geological Survey Open-File Report 2010-1172, 12 p. and database [http://pubs.usgs.gov/of/2010/1172/].

Any use of trade, product, or firm names is for descriptive purposes only and does not imply endorsement by the U.S. Government.

Although this report is in the public domain, permission must be secured from the individual copyright owners to reproduce any copyrighted material contained within this report. 


\section{Contents}

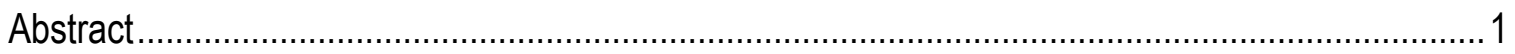

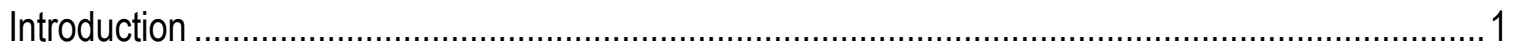

Structure of the database

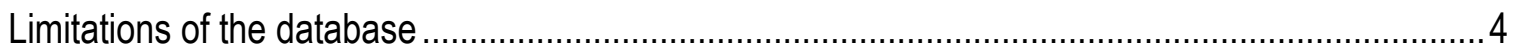

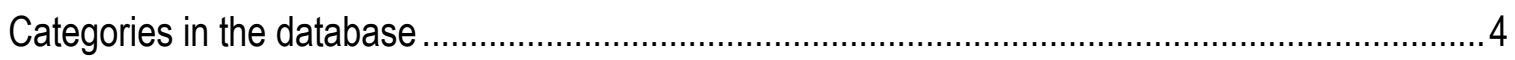

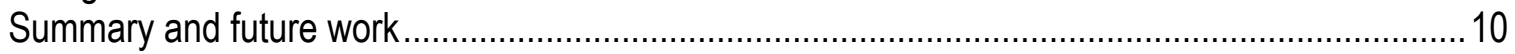

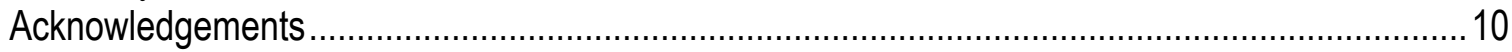

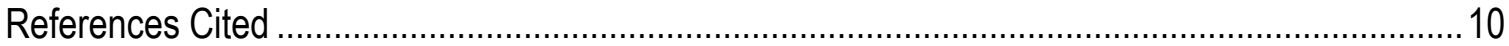




\title{
Recent Tsunami Deposit Database
}

\author{
By Robert Peters and Bruce E. Jaffe
}

\begin{abstract}
This report describes a database of sedimentary characteristics of tsunami deposits derived from published accounts of tsunami deposit investigations conducted shortly after the occurrence of a tsunami. The database contains 228 entries, each entry containing data from up to 71 categories. It includes data from 51 publications covering 15 tsunamis distributed between 16 countries. The database encompasses a wide range of depositional settings including tropical islands, beaches, coastal plains, river banks, agricultural fields, and urban environments. It includes data from both local tsunamis and teletsunamis. The data are valuable for interpreting prehistorical, historical, and modern tsunami deposits, and for the development of criteria to identify tsunami deposits in the geologic record.
\end{abstract}

\section{Introduction}

Tsunami deposits provide important information regarding the potential hazard, past occurrence, recurrence, and magnitude of tsunamis. Tsunami deposits have been used in the preparation of tsunami hazard maps (Priest and others, 1997; Walsh and others, 2000), in probabilistic studies used for modernizing flood hazard maps (Tsunami Pilot Study Working Group, 2006), and are an important part of evaluating sites for future nuclear power plants (Moore and Jaffe, 2007) and other potentially hazardous coastal installations, such as liquid natural gas facilities (Ross and others, 2004). Tsunami deposits preserved in the geologic record have been important in alerting scientists and the public to potential tsunami and earthquake hazards where the historical record is too short to include prior tsunami events (Satake and others, 1996). Tsunami deposits have the potential to provide information on tsunami overland flow velocities and wave heights, information that is often difficult to measure or estimate even immediately after a tsunami has occurred (Jaffe and Gelfenbaum, 2007).

An important consideration in any tsunami deposit field study is developing criteria to identify tsunami deposits and to distinguish tsunami deposits from sediments deposited by storms or other processes. Criteria for identification of tsunami deposits have been established and published over the last two decades (Nelson and others, 1996; Dawson and Shi, 2000; Moore and Jaffe, 2007; Peters and others, 2007). Several studies address the issue of distinguishing tsunamis from storm deposits (Nanayama and others, 2000; Goff and others, 2004; Tuttle and others, 2004; Kortekaas and Dawson, 2007; Morton and others, 2007). Tsunami deposit characteristics also have been defined based on numerical modeling of tsunami depositional processes (Jaffe and Gelfenbaum, 2007). Modeling studies usually rely on a set of idealized or simplified parameters or assumptions (Jaffe and Gelfenbaum, 2007). These conditions may not apply to the whole tsunami deposit and may be missed in isolated cores typical of paleotsunami surveys. 
Criteria based on sedimentary characteristics of paleotsunami deposits use characteristics of interpreted rather than known tsunami deposits (Dawson and Shi, 2000). Many studies have recognized the need to use modern tsunami deposits to develop criteria for identifying paleotsunami deposits (Nanayama and others, 2000; Kortekaas and Dawson, 2007; Morton and others, 2007). However, criteria based on modern tsunami deposits are limited to specific regions and tsunamis.

No single criterion is sufficient to identify a tsunami deposit. Identification criteria must be used in combination to determine if a deposit is consistent with tsunami deposition and to eliminate other depositional processes. Rarely do tsunami deposits, as observed in the field in trenches, outcrops, or cores, contain all of the sedimentary characteristics used in these identification criteria, and deposits originated by other coastal processes, such as storms, often share characteristics with tsunami deposits (Kortekaas and Dawson, 2007; Morton and others, 2007). Differences in tsunami deposits due to regional or even local differences in depositional, physiographic, and tectonic settings, as well as differences between tsunamis responsible for the deposits, complicate the problem of developing a single set of identification criteria that can be used in all tsunami deposit studies. While most recent tsunami deposit studies confirm a number of established tsunami deposit identification criteria, at least locally, they also show a great diversity from site to site and between tsunamis. To be most effective, tsunami deposit identification criteria must be tailored to each individual study and should be based, at least in part, on a set of sedimentary characteristics derived from observations of known recent tsunami deposits, ideally from similar settings.

To facilitate development of identification criteria based on sedimentary characteristics derived from known tsunami deposits, the recent tsunami deposit database compiles data derived from published reports that encompass most known recent tsunami deposits. For the purposes of this database, recent tsunami deposit studies are studies that include descriptions of the characteristics of the tsunami deposit, and where the descriptions are made soon after the tsunami occurred, to minimize reworking of the deposit. In a recent tsunami deposit survey, identification of the tsunami deposit is often simple, and characteristics of the deposit may be recorded with little doubt of its origin. A possible exception to this is where the tsunami deposit is deposited directly over beach sand, and the location of the basal contact may involve some interpretation (Jaffe and others, 2003). While no specific time limit can be assigned in defining a recent tsunami deposit, the time elapsed between the tsunami and the field investigation should be short enough that identification of the tsunami deposit is not in question and the tsunami deposit has been minimally altered by natural or anthropogenic activity. In contrast, a historical tsunami deposit is a deposit from a known tsunami that occurred in the historical past that must be identified and interpreted from an outcrop, core, or trench, while a paleo-tsunami deposit records a tsunami that predates the historical record.

Descriptions of tsunami sediments are relatively new in the literature. Shepard and others (1950) reported sediments on roadways in Hawaii following the 1946 Alaska earthquake and tsunami. Sediments deposited in Hawaii, Japan, and Chile by the 1960 Chile tsunami were described by Eaton and others (1961), Kon'no (1961), and Wright and Mella (1963), respectively. Following the interpretation of sand layers in salt marsh stratigraphy along the Niawiakum River in southwest Washington as tsunami deposits (Atwater, 1987), a large number of papers were published describing tsunami deposits 
both in Cascadia and worldwide. Following the December 12, 1992, tsunami on Flores, Indonesia, tsunami-deposited sediments were described by Shi and others (1995).

Tsunami sediments also were described following the July 12, 1993, Hokkaido-NanseiOki tsunami in Japan by Nishimura and Miyaji (1995) and Sato and others (1995). Tsunami sediment studies have followed every major tsunami since. The SumatraAndaman tsunami of December 26, 2004, initiated an unprecedented number of posttsunami field surveys, a large number of which included detailed tsunami sediment investigations. Most post-tsunami field surveys now include a sedimentary component and the quantity and quality of sedimentary data has steadily increased. The body of recent tsunami sediment data now encompasses a large number of depositional, physiographic, and geologic settings. The database presented here contains 228 entries. Each entry represents a specific site from a specific study and is derived from the body of published literature on tsunami deposits. The data are organized into 71 categories and contain data about the deposits, the tsunamis, the sites, and the methods used to collect the data. The database includes data from 51 publications documenting deposits from 15 tsunamis distributed over 16 countries worldwide.

\section{Structure of the Database}

This recent tsunami deposit database uses the Microsoft Excel spreadsheet program to present and organize the data. The database is set up on two Microsoft Excel worksheets. The first worksheet describes tsunami deposits. The second is a list of the full references for papers cited in the database. The data format used in each of the included papers often varies from publication to publication. We have used numerical data, wherever possible, and when this is not available, we have used the authors' own words or descriptions. Where conversions are clear, we have converted data into standard formats appropriate for the category, such as decimal degrees for latitude and longitude or centimeters for deposit thickness. If a publication describes more than one site, and if details for each site are given separately, each site is catalogued separately (that is a separate row is used for each deposit). Also, separate entries may be used if specific data apply to clearly defined cores, trenches, or transects. If only generalized data are given that apply to more than one site, sites may be grouped into a single entry. Generalized data are included for individual sites if it is clear that the data apply to that site. If significant differences in deposit characteristics are reported at different locations within a site, these also are catalogued separately.

None of the publications cited in the database cover all data categories. Many publications are limited in scope and cover only a few categories. In others, tsunami deposits were only a secondary theme of the paper. For some sites, there is only mention that a tsunami or storm deposit was present, but no details are given. Some categories are present in the database that do not contain any entries. These categories are included because data appropriate to the category is included in other databases (for example, the Cascadia tsunami deposit database; Peters and others, 2003) and the category is included for comparison, or because the data may be useful in evaluating tsunami deposits. The database categories provide a guide to the type of data useful in tsunami deposit studies and to the type of data that needs to be recorded in the field and included in publications describing tsunami deposits. 


\section{Limitations of the Database}

Care should be exercised in using these data. No attempt has been made to verify the data presented in this report. The data are derived from a variety of studies with differences in focus, scope, and intent. Details concerning techniques, errors, difficulties, inconsistencies, and potential alternate interpretations of the data are beyond the scope of this report. These are usually site-specific and the original citation should be consulted regarding the context of the data. This report contains data from both peer-reviewed journals and from publications not typically subjected to extensive peer review, such as technical papers or conference proceedings. Abstracts are not used in the database. A column for the type of publication is included in the database. While the degree of conformity to standard methods has increased as tsunami deposit studies have become more common, techniques still varied widely among the studies and the accuracy and precision between separate entries may not be comparable. No attempt has been made in this report to quantify errors. It is recommended that the original reference, supplied for each entry, be consulted before using data compiled in this report.

\section{Categories in the Database}

Entry number: The number of the entry in the database.

Country: The country where the site is located.

Location - general: The state, city, or other regional designation used to locate the site of the deposit.

Site name - specific: The specific name of the site investigated. If more than one site is listed and coordinates apply to only one location, or if coordinates are supplied for more than one site, coordinates will be assigned in the order of the sites listed and sites with coordinates will be denoted by an asterisk (*). In some cases, general data are given for a wide area in one entry labeled "general", then specific data are given for specific site, transects, or cores in subsequent entries.

Transect number or designation: If data are derived from a single or group of transects, and multiple transects or groups of transects exist at the site, a transect designation is included. If the data represent a compilation or condensation of data derived from all transects, no transect designation is given.

Core or trench number: The core or trench designation, or group of cores or trenches, that the data are derived from.

Latitude (decimal degrees): Latitude of site where data were collected. The most precise location supplied by the authors is used. For example, if location data for a specific core or trench are supplied, this will be used. If not, site location data will be used. If multiple locations are given for a single entry, such as GPS coordinates for a group of cores or transects, a representative latitude or a range will be given.

Longitude (decimal degrees): Longitude of site where data were collected. The most precise location supplied by the authors is used. For example, if location data for a specific core or trench are supplied, this will be used. If not, site location data will be used. If multiple locations are given for a single entry, such as GPS coordinates for a group of cores or transect, a representative latitude or a range will be given. 
Source of location data: Latitudes and longitudes reported by the authors are used, when possible, either from the primary publication or directly from one of the authors of the publication. If location data are not supplied by the author, Google Earth or Google Maps were used to derive a general location based on place names supplied by the authors. Some locations were too general to assign coordinates. Latitudes and longitudes other than those supplied by the authors are for general location reference only and may not precisely or accurately represent a site location.

Date surveyed: dates, year, or period survey was conducted.

Method of investigation (field methods): The method used to investigate tsunami sedimentation. Common investigative methods are trenches, gouge cores, cut banks, for example. Specific field methods may not be presented here, and the original citation should be consulted for details.

Laboratory analyses performed: List of technical analyses performed on samples from the deposit, such as grain size or foraminiferal. Specific analytical techniques are not presented here, and the original citation should be consulted for details.

Depositional setting: Depositional setting for tsunami or storm sedimentation, such as lake, coastal marsh, freshwater marsh, for example.

Physiographic setting: The physiographic setting in which the tsunami deposits are located. The physiographic setting affects the flow conditions of the tsunami, and, therefore, sedimentation. Physiographic setting also may influence how some tsunami parameters, such as inundation, are measured. Some aspects of the geologic setting may be presented as well.

Inundation reference: Inundation distance for open coastal settings is the maximum distance inland, normal to the shoreline, inundated by the tsunami. However, in other physiographic settings, the term inundation distance is subject to interpretation and the definition may change depending on the focus of the study. In a large bay or estuary, which may extend several kilometers inland from the open coast, a tsunami may propagate up a bay or even be focused by the bay. A tsunami that has a relatively small inundation distance in an open coastal setting or along a coast with cliffs may travel a greater distance up a river or estuary. Therefore, when considering inundation distance, it is important to note the physiographic setting and the reference point from which inundation distance is measured. When known, the reference point for measuring the inundation distance is given. "Open coast" means the inundation distance is measured normal to the trend of the shoreline. When warranted, a more specific reference may be given. "River mouth" means the distance is measured from the mouth of the river or estuary, perpendicular to the trend of the coast at the river mouth. "Up river" means the distance up a river or estuary and will not necessarily be in a straight line but will follow the course of the river. "Bay shore" means perpendicular to the trend of the shore within a bay. When "bay shore" is added to river descriptions it means the distance is measured from the mouth of a river that flows into a bay.

Barrier height (m): The height, in meters, of any barrier, such as a dune or beach ridge, that the tsunami must overtop before reaching the depositional zone. 
Recent, historical, or prehistorical: All entries in this database are recent tsunami deposits. This column is included for comparison with other databases. Though these terms may infer a relative age for a deposit, they do not refer to a specific time period. "Recent" indicates that data were collected soon after the sediment was deposited. No criteria have been established yet in the literature to define or limit the time period termed "recent", but for an event termed "recent", tsunami sediment survey teams are organized soon after an event to document, measure and/or sample sediment before it has been disturbed by natural or anthropogenic processes. Ideally, this is immediately after the event, but if the event causes significant damage or loss of life, sediment survey teams usually arrive after initial relief efforts have been completed. A recent event is usually present at the surface. Follow-up studies occurring months to years after the event also may be termed "recent". "Historical" refers to events recorded in the historical record that are recognized in the sedimentary record. "Prehistorical" refers to events only known through the sedimentary record.

\# Tsunamis at site: At some sites, more than one recent tsunami deposit was documented. Some studies also included a paleotsunami component to the investigation. The number of tsunamis preserved in geologic record at the site, from the surface to the maximum depth investigated is listed here. However, no details of historical or paleo-tsunami deposits are included in the database, even if they occur at the same site as a recent tsunami deposit.

Event \#: If more than one event is preserved, this entry represents the number of the tsunami event described. Event numbers increase down-core or section. At present, all events included in the database are recent. At some sites, more than one recent tsunami deposit was documented. MacInnes and others, (2009) report results from deposits by two recent tsunamis from the Kuril Islands. The most recent tsunami (January 13, 2007 is assigned event \# 1 and the earlier tsunami (November 15, 2006) is assigned event \# 2. Jaffe and others (2006) report two recent tsunamis on the island of Simeulue, Indonesia, but only data from the December 26, 2004, tsunami was presented in the report, so only results from the December 26, 2004, tsunami (event \# 1) is included in the database.

Date of tsunami: The date the tsunami occurred.

Name/designation of tsunami: The name or designation of the tsunami. This often is the name of the region the tsunami originated or the area of its greatest impact. If more than one name is reported in the literature, the most accepted name is reported.

Recurrence interval: If historical or paleotsunami surveys at the site allow calculation of a recurrence interval for tsunamis at the site, it is reported here. Recurrence intervals based on methods other than tsunami deposits are not reported.

Cause of tsunami: A summary of the cause of the tsunami, such as earthquake, submarine landslide, or volcano.

Locally generated or teletsunami: This entry designates if the tsunami was generated locally, relative to the site being described, or has traveled long distances or across ocean basins.

Tsunami height (m): The reported size, in meters, of the tsunami at the site location. This statistic represents the size of the wave relative to sea level. It is different than the water depth, which is reported relative to ground level. 
Tsunami water depth at site (m): The maximum depth, in meters, of the water caused by the tsunami above the ground surface, estimated at the site, transect, core, or trench location. Surveys may use physical data, eyewitness reports, or a combination of the two to estimate water depth. Physical evidence may be broken branches, sediment deposits on structures, debris in trees, trim lines, or water marks. These are usually minimum estimates. Estimates based on eyewitness reports may overestimate or underestimate water depth. Original reference should be consulted for methods used to estimate water depth data. Water depth is different than tsunami height, which is measured relative to sea level.

\# Waves reported: The number of waves reported to have inundated the site. This may be from eye-witness accounts or interpreted from the tsunami deposit.

Maximum inundation at site (m): The maximum inland extent of wave inundation, in meters, at the site (see "inundation reference").

Maximum run-up (m): The elevation of wave inundation at the limit of inundation at the site, in meters above mean sea level unless otherwise noted.

Maximum inland extent of sedimentation (m): The shore-parallel extent of tsunamideposited sediment, in meters at a site. If a specific flow path is indicated, distance may be described along the flow path. Any change from shore-normal distance will be noted and described.

Lateral extent of sedimentation $(\mathrm{km})$ : The shore-parallel extent of sediment, in kilometers at a site. Any change from shore-parallel in this column will be noted and described.

Maximum sediment elevation (m): The maximum elevation of sediment at a site or along a transect, in meters above sea level.

Distance from shore to deposit investigated (m): The distance, in meters, to site of core or trench where deposits are described. Unless otherwise noted, the distance is shorenormal. Any deviation from shore-normal distance will be noted and described.

Deposit Elevation (m): The elevation of land surface at site of core or trench where deposits are described, in meters above sea level.

Geometry: The two and three-dimensional characteristics of the deposit describing the shape and extent of the deposit, such as landward thinning, hummocky, or sand sheet. The entry may include descriptions of lateral changes in thickness and brief discussions of controlling factors.

Deposit Thickness (cm): The tsunami deposit thickness, in centimeters.

Vertical reference: Measurements or descriptions are often referenced to the top, bottom, or a specific location within the deposit. This entry defines where subsequent vertical measurements are referenced to (that is $0 \mathrm{~cm}=$ base of deposit, top of deposit, surface, or other reference as given in the publication).

\# Layers: The number of distinct layers or beds within the deposit.

Layer thickness (cm): If more than one layer is present, the thickness, in centimeters, of the individual layers within the deposit (layer thickness of a single layer deposit is "deposit thickness" above). If layer numbers are assigned and used throughout the publication, layer numbers correspond to those used in the publication. If the author presents no numbering scheme and a vertical reference is indicated, layer numbers increase from the vertical reference. If no vertical reference is indicated, layer one corresponds to the uppermost layer in the sequence and layer numbers increase down-section. 
Layer characteristics: Sedimentary characteristics of the individual layers as described in the publication. Layer numbers correspond to and/or follow the criteria used for "layer thickness" above.

Underlying material: A description of the material directly below the deposit.

Basal contact: The nature of the basal contact of the deposit, including vertical rate of change (gradual, sharp, or abrupt) and process-oriented descriptions (such as erosional), or other descriptions relating to the nature of the contact.

Overlying material: A description of the material overlying the deposit. Overlying material is usually absent in a recent tsunami deposit. However, if enough time has passed between the event and the investigation, and if the deposit is in a depositional (as opposed to an erosional) setting, sediments may overly a recent deposit.

Upper contact: If the deposit is covered by overlying material, this describes the nature of the upper contact of the deposit, including vertical rate of change (gradual, sharp, or abrupt) and process-oriented descriptions (such as erosional), or other descriptions relating to the nature of the contact.

Surface features: Features (such as ripples or mud cracks) present at the upper surface of the deposit.

Grain size statistics - mean: This column is reserved for numerical statistics, although it may contain text qualifiers.

Grain size statistics - median: This column is reserved for numerical statistics, although it may contain text qualifiers.

Grain size statistics - mode: This column is reserved for numerical statistics, although it may contain text qualifiers.

Grain size statistics - standard deviation: This column is reserved for numerical statistics, although it may contain text qualifiers.

Grain size statistics - skewness: This column is reserved for numerical statistics, although it may contain text qualifiers.

Grain size statistics - kurtosis: This column is reserved for numerical statistics, although it may contain text qualifiers.

Grain size - text descriptions: A description of sediment grain size condensed from publication text. Text descriptions of grain sizes for the sand fraction often follow the Udden-Wentworth scale (Udden, 1914; Wentworth, 1922). Conversions between phi, millimeters, and text descriptions based on Udden-Wentworth are given by the following conversions:

very coarse sand $=1.000-2.000 \mathrm{~mm}=0.0--1.0 \mathrm{phi}$

coarse sand $=0.500-1.000 \mathrm{~mm}=1.0-0.0 \mathrm{phi}$

medium sand $=0.250-0.500 \mathrm{~mm}=2.0-1.0 \mathrm{phi}$

fine sand $=0.125-0.250 \mathrm{~mm}=3.0-2.0 \mathrm{phi}$

very fine sand $=0.062-0.125 \mathrm{~mm}=4.0-3.0 \mathrm{phi}$

Granules to boulders: Grain sizes larger than the sand fraction present in the deposit, including granules, pebbles, cobbles, and boulders.

Mud, clay or silt: Grain sizes smaller than the sand fraction present in the deposit, including silt, clay, or an unspecified combination (mud). 
Vertical grading: Vertical changes in grain size distribution. Grading descriptions may describe the whole deposit or individual or specific beds or portions of the deposit. Normal grading fines upward; reverse grading coarsens upward; massive indicates no discernable changes in grain size or bedding.

Lateral grading: Changes in grain size laterally within the deposit, such as landward coarsening or fining.

Mode - text descriptions: Text descriptions of the mode or modes of the grain size distribution of the deposit. No attempt is made in this column to interpret numerical statistics.

Sorting - text descriptions: Text descriptions of grain size sorting within the deposit. Sorting may be statistically described by the standard deviation of the grain size distribution. Numerical calculations of standard deviation (sorting) are given in a separate column. Well-sorted deposits contain a narrow range of grain sizes; poorlysorted deposits contain a wide range of grain sizes.

Skewness - text descriptions: Text descriptions of the skewness of the grain size distribution of the deposit. No attempt is made in this column to interpret numerical statistics.

Kurtosis - text descriptions: Text descriptions of the kurtosis of the grain size distribution of the deposit. No attempt is made in this column to interpret numerical statistics.

Grain texture: Texture descriptions, excluding grain size (given previously), including angularity and surface roughness of the grains comprising the deposit.

Other sedimentary structures or properties: Other sedimentary characteristics or properties of the deposit described by the authors.

Composition: Mineralogical or chemical composition or lithic descriptions of the deposits.

Microflora and microfauna - foraminifera, diatoms, for example: Foraminifera, diatoms, and other microfossil assemblages within the deposit. This entry also may list any changes or similarities between the deposit and underlying and overlying material or surrounding environments. It is beyond the scope of the database to list all species below, within, or above the deposit. General results of diatom analyses are presented here. Individual publications should be consulted for specific data.

Pollen: Changes in pollen assemblages between the underlying material, the tsunami or storm deposit, and the overlying material, can help determine sediment source and post-event environmental changes to the depositional system. It is beyond the scope of the database to list all species below, within, or above the deposit. General results of pollen analyses are presented here. Individual publications should be consulted for specific data.

Macroscopic organics: Macroscopic organic inclusions in the deposit, such as shells, roots, woody debris, vegetation, and peat are listed here.

Flow direction: If a flow direction has been determined by the authors, it is listed here. Flow direction may be a compass direction, may be referenced to a point, or may be descriptive, such as landward, return flow, or shore-parallel.

Additional comments or data: This column is for any additional information pertaining to the data, qualifying data presented, or for any additional data that does not fit into the preceding categories. 
Reference: Reference for the report the data are derived from. Full references are provided on the second worksheet of the database.

Reference type: The type of publication (such as peer-reviewed journal, conference proceedings, U.S. Geological Survey report, or technical paper) the paper is published in.

\section{Summary and Possible Future Research}

Investigations of sedimentary deposits from recent tsunamis are important in developing identification criteria for paleotsunami deposits and in interpreting both recent and paleotsunami deposits. Recent tsunami deposits have an advantage because the deposits are easily identified and may be correlated with data from the tsunami that deposited the sediment. This recent tsunami deposit database compiles data from published reports of tsunami deposit surveys, documenting sedimentary characteristics and tsunami data from 15 events that have occurred since 1946. The database contains 228 entries. Each entry contains data from up to 71 categories. The database includes data from 51 publications describing recent tsunami deposits from 16 countries.

Future research might include analyzing the data in this database. Trends could be examined within the database, to determine both the range and typical values observed for selected sedimentary characteristics, and identification criteria for tsunami could be determined for deposits based on the recent tsunami deposit data presented here.

\section{Acknowledgments}

The U.S. Nuclear Regulatory Commission and the U.S. Geological Survey Coastal and Marine Catastrophic Hazards Project funded this research. The views expressed are not necessarily those of the U.S. Nuclear Regulatory Commission. Susan Cochran and Steve Watt provided thoughtful reviews that improved this report.

\section{References Cited}

Atwater, B., 1987, Evidence for great Holocene earthquakes along the outer coast of Washington State: Science, v. 236, p. 942-944.

Dawson, A.G. and Shi, S.Z., 2000, Tsunami deposits: Pure and Applies Geophysics, v. 157 , p. $875-897$.

Eaton, J. P., Richter, D.H., and Ault, W.U., 1961, The tsunami of May 23, 1960, on the Island of Hawaii: Seismological Society of America Bulletin, v. 51, p. 135-157.

Goff, J., McFadgen, B.G., and Chague-Goff, C., 2004, Sedimentary differences between the 2002 Easter storm and the 15th-century Okoropunga tsunami, southeastern North Island, New Zealand: Marine Geology, v. 204, p. 235-250.

Jaffe, B., and Gelfenbaum, G., 2007, A simple model for calculating tsunami flow speed from tsunami deposits: Sedimentary Geology, v. 200, p. 347-361.

Jaffe, B., Gelfenbaum, G., Rubin, D., Peters, R., Anima, R., Swensson, M., Olcese, D., Bernales L., Gomez, J., and Riega, P., 2003, Tsunami deposits-Identification and interpretation of tsunami deposits from the June 23, 2001, Perú tsunami: Coastal Sediments '03 Proceedings, $13 \mathrm{p}$. 
Jaffe, B.E., Borrero, J.C., Prasetya, G.S., Peters, R., McAdoo, B., Gelfenbaum, G., Morton, R., Ruggiero, P., Higman, B., Dengler, L., Hidayat, R., Kingsley, E., Kongko, W., Lukijanto, Moore, A., Titov, V., and Yulianto, E., 2006, Northwest Sumatra and offshore islands field survey after the December 2004 Indian Ocean tsunami: Earthquake Spectra, v. 22, p. S105-S135.

Kon'no, E., Iwai, J., Kitamura, N., Kotaka, T. Mii, H. Nakagawa, H. Onuki, Y. Shibata T. and Takayanagi, Y., 1961, Geological observations of the Sanriku coastal region damaged by the tsunami due to the Chile earthquake in 1960 (in Japanese with English abstract): Contributions from the Institute of Geology and Paleontology, Tohoku University, v. 52, 40 p.

Kortekaas, S. and Dawson, A.G., 2007, Distinguishing tsunami and storm deposits-An example from Martinhal, SW Portugal: Sedimentary Geology, v. 200, p. 208-221.

MacInnes, B.T., Pinegina, T.K., Bourgeois, J., Razhigaeva, N.G., Kaistrenko, V.M., Kravchunovskaya, E.A., 2009, Field Survey and Geological Effects of the 15 November 2006 Kuril Tsunami in the Middle Kuril Islands: Pure and Applied Geophysics, v. 166, p. 9-36.

Moore, A., and Jaffe, B., 2007, Geologic evidence of tsunamis, in Gonzalez, F.I., Scientific and technical issues in tsunami hazard assessment of nuclear power plant sites: NOAA Technical Memorandum OAR PMEL-136, Pacific Marine Environmental Laboratory, Seattle, Wash., 125 p. plus appendices on CD.

Morton, R., Jaffe, B., and Gelfenbaum, G., 2007, Physical criteria for distinguishing sandy tsunami and storm deposits using modern examples: Sedimentary Geology, v. 200, p. 184-207.

Nanayama, F., Shigeno, K., Satake, K., Shimokaka, K., Koitabashi, S., Miyasaka, S., and Ishii, M., 2000, Sedimentary differences between the 1993 Hokkaido-Nansei-Oki tsunami and the 1959 Miyakojima typhoon at Taisei, southwestern Hokkaido, northern Japan: Sedimentary Geology, v. 135, p. 255-264.

Nelson, A.R., Shennan, I., and Long, A., 1996, Identifying coastal subsidence in tidal wetland stratigraphic sequences at the Cascadia subduction zone of western North America: Journal of Geophysical Research, v. 101, no. B3, p. 6115-6135.

Nishimura, Y. and Miyaji, N., 1995, Tsunami deposits from the 1993 southwest Hokkaido earthquake and the 1640 Hokkaido Komagatake eruption, northern Japan: Pure and Applied Geophysics, v. 144, p. 719-733.

Peters, R., Jaffe, B., and Gelfenbaum, G., 2007, Distribution and sedimentary characteristics of tsunami deposits along the Cascadia margin of western North America: Sedimentary Geology, v. 200, 372-386.

Peters, R., Jaffe, B., Gelfenbaum., G., and Peterson, C., 2003, Cascadia tsunami deposit database: U.S. Geological Survey Open-File Report 03-13. 23 p.

Priest, G.R., Myers, E., Baptista, A., Kamphaus, R., and Peterson, C.D., 1997, Tsunami hazard map of the Yaquina Bay area, Lincoln County, Oregon: Oregon Department of Geology and Mineral Industries Interpretive Map Series IMS-2, 1 sheet, scale 1:12,000.

Ross, S., Boore, D.M., Fisher, M.A., Frankel, A.D., Geist, E.L., Hudnut, K.W., Kayen, R.E., Lee, H.J., Normark, W.R., and Wong, F.L., 2004, Comments on potential geologic and seismic hazards affecting coastal Ventura County, California: U.S. Geological Survey Open-File Report 2004-1286. 20 p. 
Satake, K., Shimazaki, K., Tsuji, Y. and Ueda, K., 1996, Time and size of a giant earthquake in Cascadia inferred from Japanese tsunami record of January 1700: Nature, v. 379, p. 246-249.

Sato, H., Shimamoto, T., Tsutsumi, A., and Kawamoto, E., 1995, Onshore tsunami deposits caused by the 1993 southwest Hokkaido and 1983 Japan-Sea earthquakes: Pure and Applied Geophysics, v. 144, p. 693-717.

Shepard, F. P., Macdonald, G.A., and Cox, D.C., 1950, The tsunami of April 1, 1946: University of California, Scripps Institute, Oceanography Bulletin, v. 5, p. 391528.

Shi, S., Dawson, A.G. and Smith, D.E., 1995, Coastal sedimentation associated with the December 12th, 1992 tsunami in Flores, Indonesia, Pure and Applied Geophysics, v. 144 , p. $525-536$.

Tsunami Pilot Study Working Group, 2006, Seaside, Oregon Tsunami Pilot Study Modernization of FEMA flood hazard maps: Joint NOAA/USGS/FEMA Special Report, NOAA/OAR/PMEL, Seattle WA, 94 p. plus 7 appendices.

Tuttle, M.P., Ruffman, A., Anderson, T., and Jeter., H., 2004, Distinguishing tsunami from storm deposits in Eastern North America-The 1929 Grand Banks tsunami versus the 1991 Halloween storm: Seismological Research Letters, v. 75, p. 177131.

Udden, J.A., 1914, Mechanical composition of clastic sediments: Geological Society of America Bulletin, v. 25, p. 655-644.

Walsh, T.J., Caruthers, C.G., Heinitz, A.C., Meyers, E.P., III, Baptista, A.M., Erdakos, G.B., and Kamphaus, R.A., 2000, Tsunami hazard map of the southern Washington coast - Modeled tsunami inundation from a Cascadia subduction zone earthquake: Washington Division of Geology and Earth Resources, Geologic Map GM-49.

Wentworth, C.K., 1922, A scale of grade and class terms for clastic sediments: Journal of Geology, v. 30, p. 377-392.

Wright, C. and Mella, A., 1963, Modifications to the soil pattern of south-central Chile resulting from seismic and associated phenomena during the period May to August 1960: Bulletin of the Seismological Society of America, v. 53, p. 1,3671,402 . 